\title{
New Surgical Approach to Common Digital Neuroma with Combined Technique of Nerve Decompression, Dorsal Nerve Transposition and Nerve Wrap in the Foot
}

\author{
Edgardo Rodriguez-Collazo, Carl M. Jean* and Gerard A. Leotaud \\ DPM, New York Presbyterian Brooklyn Methodist Hospital, USA
}

Submission: April 24, 2017; Published: May 12 , 2017

*Corresponding author: Carl Jean, DPM, New York Presbyterian Brooklyn Methodist Hospital, 506 6th Street Brooklyn, NY 11216, USA,

Tel: 646-453-9331; Email: c007jean@aol.com

\begin{abstract}
A prospective study was done to evaluate the treatment of neuromas in the foot with a combined technique of neurolysis or decompression of the common digital nerve, dorsal nerve transposition and nerve wrap in the foot. Patient success was based on extent of pain after surgery, ability to wear regular shoes, and ability to return to work.
\end{abstract}

\section{Introduction}

A common digital neuroma in the foot, commonly known as Morton's Neuroma is a well-established entity. It is thought to be related to an area of high pressure or movement. As a result, clinical symptoms of neuralgia and metatarsalgia can often result. It is widely believed that the common digital neuroma in the foot is caused by increased pressure on the nerve [123]. Injury may be caused by the metatarsal heads, pressure by the deep transverse metatarsal ligament or an intermetatarsal bursa. Over time, if the compression/injury continues, the nerve repairs itself with fibrous tissue that leads to enlargement and thickening of the nerve. Current mainstream surgical techniques include decompression, neurolysis and neurectomy.

The specific case highlighted in this article is that of a 63 -year-old female who presented with radiating pain to the left third and fourth digits. Patient had positive paresthesias to the left third and fourth digits. The patient also had a positive Mulder's click. Patient failed conservative techniques which included, wrapping/strapping, cortisone injections, shoe gear modification and orthotics. On March 3, 2015, an MRI of the left foot was performed. The MRI noted that, "There is a 1.2 $\mathrm{cm}$ signal abnormality within the third interspace. This area is fairly isointense to muscle on $\mathrm{T} 1$ and proton density and is compatible with a Morton's neuroma." Patient underwent this newly described surgical procedure on June 16, 2015.

\section{Method}

A linear or lazy-S type of line is draw along the skin overlying the corresponding interspace where the neuroma is located (Figure 1). A skin incision is now made. It should be noted that careful dissection is to be performed in this area as one can readily encounter crossing veins and lymphatic vessels. We do recommend using loupe magnification (Figure 1).

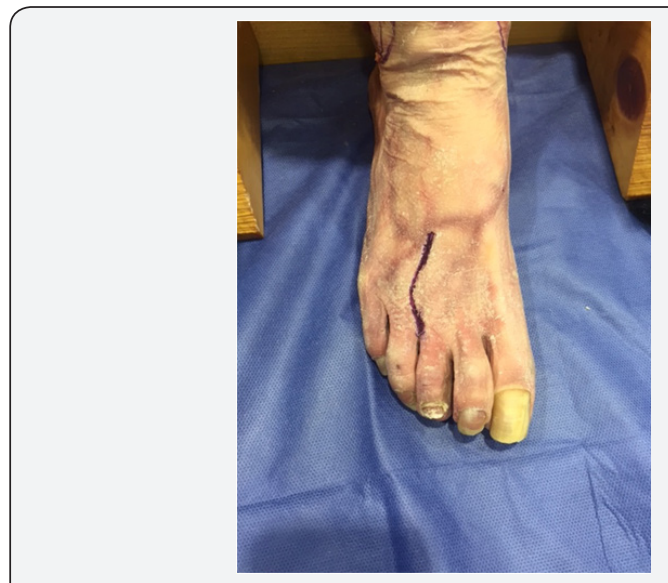

Figure 1: Cadaveric Representation.

Avoiding injury to the dorsal venous arch will often help prevent post operative forefoot edema. In some cases, these vessels can be simply retracted, if not, they should be tied off or 


\section{Orthopedics and Rheumatology Open Access Journal}

cauterized. Meticulous hemostasis is off the utmost importance. We do recommend using a pneumatic tourniquet [14] (Figures $2 \& 3)$.
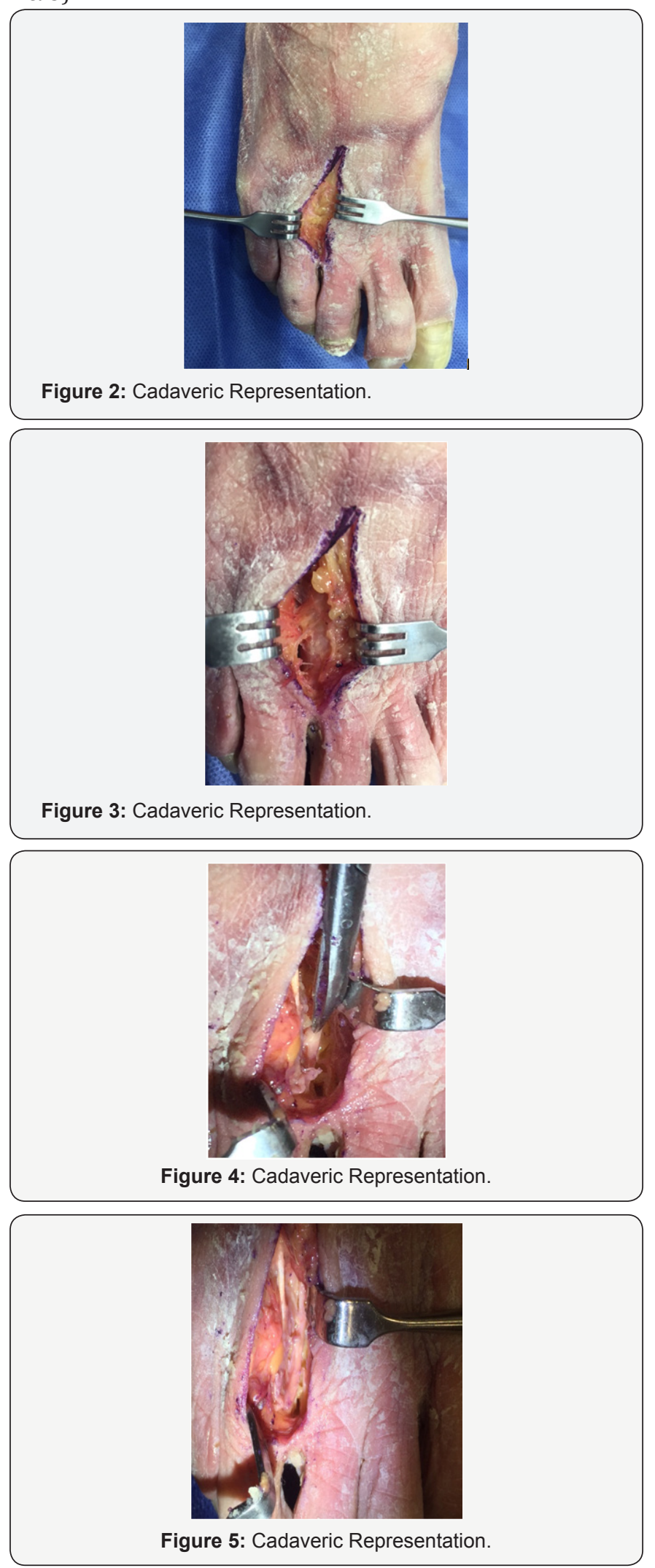

A Weitlaner self-retaining retractor can be inserted in between metatarsal heads and gently opened (Figure 2). Senn retractors or lamina spreader can also be used. Blunt dissection is performed. Upon further dissection of subcutaneous tissue, one will eventually encounter the deep transverse metatarsal ligament (Figure 3). It can be confirmed with use of a curved hemostat. This ligament should be cauterized then incised [14]. The common digital nerve will be found just inferior to this ligament. If not readily visualized, apply moderate pressure along the plantar aspect of the foot. When pressure is applied to the web space, this maneuver should help bring the nerve into the field of view (Figure 4). The nerve should now be clearly visible. Careful dissection should be performed, as it should be teased away from surrounding structures (Figure 5).

The nerve is now placed within a nerve wrap (supplied by various companies including Axogen or Integra). 7.0 Nylon or prolene is used to suture the nerve wrap in a tubular fashion. It should be noted that the appropriate nerve wrap should be used as not to strangulate the nerve. Furthermore, great care should be taken not to pass the suture through the nerve itself. Loupe magnification is very helpful during this part of the surgery. The nerve wrap may have a lot of recoil and thus it is easier to begin suturing at one end of the nerve wrap. The nerve wrap will usually uncoil itself as you continue along the length of the nerve wrap (Figures 6 \& 7).

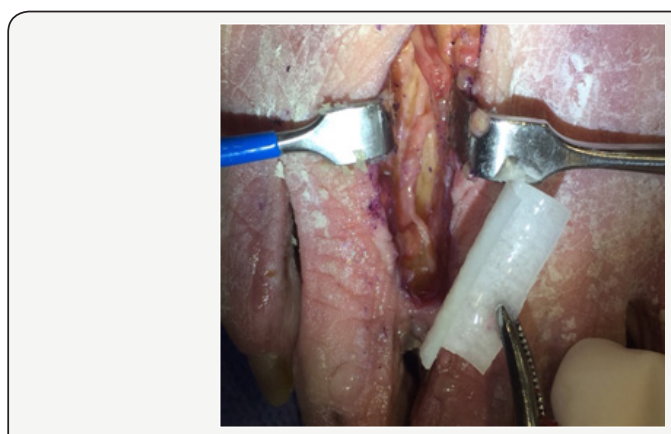

Figure 6: Cadaveric Representation.

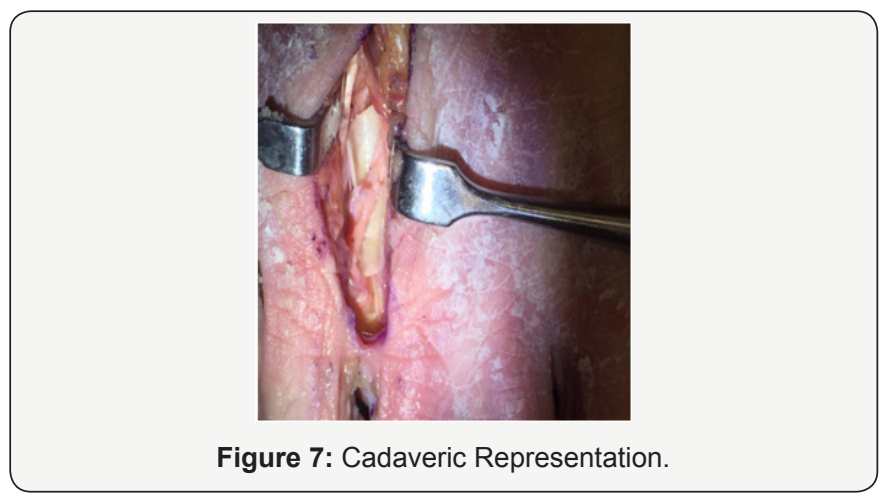

Once the nerve is fully encased within the nerve wrap, the entire construct is now transposed dorsally just slightly above the adjacent metatarsals. The nerve wrap (with the encased nerve) 
is now sutured to the adjacent muscle fascia. Subcutaneous tissue is now re-approximated with absorbable suture and skin with non-absorbable suture (Figures 8 \& 9).
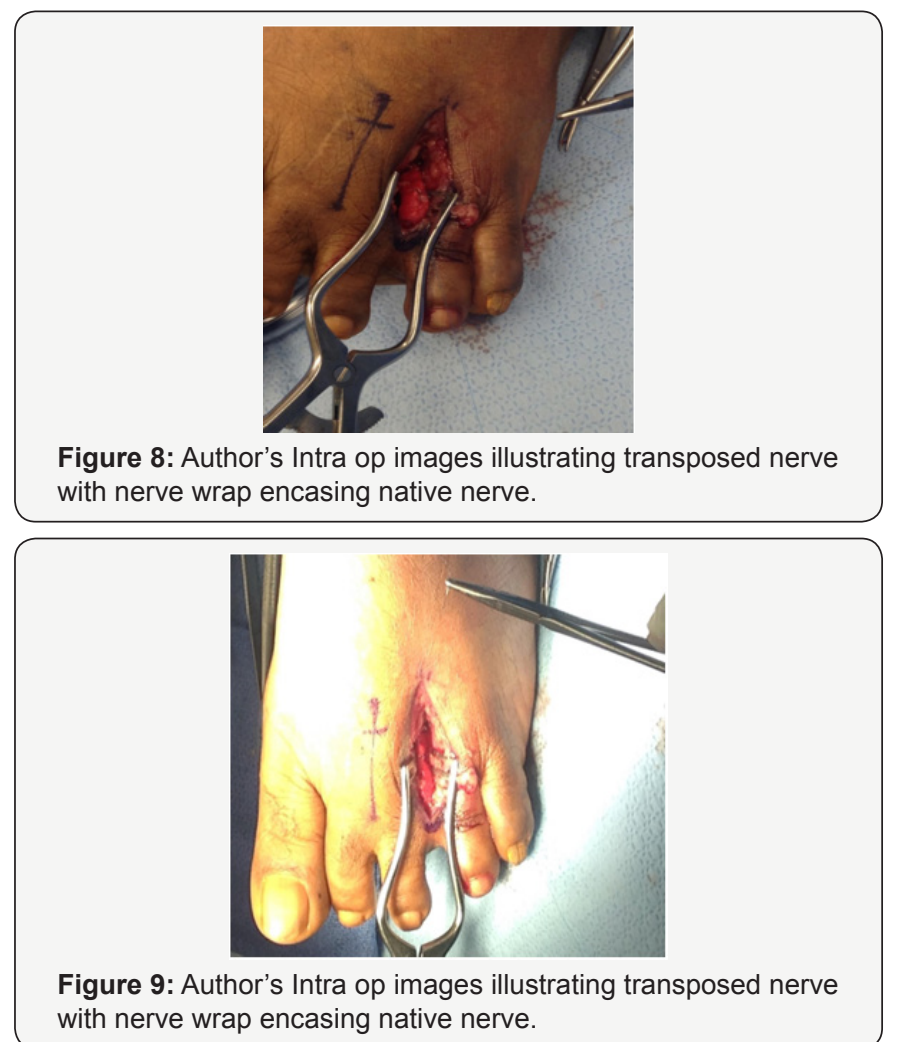

\section{Discussion}

The above patient was seen one week following the surgical procedure where she was assessed for any signs of dehiscence or post operative infection. Wound edges were well coapted. Normal post operative incisional pain and edema was noted. Patient followed up two weeks later (third week post op) where sutures were removed. On the third post operative visit (fifth week post op), patient denied any pain or tenderness to the plantar aspect of her left foot and indicated that she felt comfortable enough to the point where she actually ran on a treadmill. Again, her neuroma is $12 \mathrm{~mm}$ in size. Though use of treadmill was not recommended or encouraged, this patient's result may indicate that this technique may be a superior approach to current surgical methods.

One accepted approach is decompression of the nerve. One study [21], "fourteen decompression procedures were performed. Eleven of the 14 patients had absence of the neuroma symptoms after the decompressions. Two patients had recurrence of symptoms; the third sustained a crush injury to the operative foot. Both patients with recurrences required revision surgery because the initial procedure failed to relieve symptoms. One patient noted lack of relief in the immediate postoperative period ( 2 weeks), the other was symptom free for approximately 1 year. Only one of these individuals responded to resection of the intermetatarsal nerve, while the other continue to have pain."

Other options include neurolysis or neurectomy. A study in 2008 found that 50 patients (69 feet) underwent surgery for treatment of neuroma. Author's in this study chose between a neurolysis or neurectomy. The decision to perform either procedure was decided intra operatively. If there was macroscopic thickening or pseudoneuroma, the neuroma was resected. If there were no macroscopic findings, neurolysis was performed. In the end, 46 of these cases resulted in resection and 23 cases resulted in preservation of the nerve. Total relief was obtained except for one patient in each group which was later operated on 6 months later. In the case where the nerve was previously resected, a further more proximal resection of the nerve was performed. Author indicates that patient had complete pain relief [22].

Kyung Tai Lee et al. reviewed long term studies of neurectomy in the treatment of Morton's neuroma. This study extended over a 10-year period. Seven different studies between 1991-2008 were reviewed by this group. Dr. Lee and his group said that aside from expected numbness, they found that long lasting pain was found in many patients after surgery. Many had difficulty wearing shoes comfortably after surgery [23]. In another study author states that $51 \%$ of the patients felt they had good outcome while $40 \%$ had poor results [24]. Colgrove et al. [19] compared transposition versus resection in a randomized trial. During the nerve transposition, the nerve was transposed and positioned between the adductor halluces and the interossei muscles. At the 36- to 48-month follow-up, they found the resection group to have $86 \%$ excellent and $14 \%$ fair results; meanwhile, the transposition group had $96 \%$ excellent and $4 \%$ good results [19]. The pain level was reported on a numerical rating scale of 0 to 100 . They found that the pain in the resection group was lower during the first six months but higher at the 12-month review. They concluded that resection is unnecessary for symptom relief. However, to date, another repeat study has not been conducted to confirm their results. In addition, it should be noted that their study did not use a nerve wrap.

\section{Conclusion}

The technique discussed in this article involving neurolysis, followed by application of nerve wrap with dorsal transposition serves as a primary treatment for this condition rather than resection. This technique also did not involve a plantar approach which helped to avoid risk of painful plantar scarring. It should be noted that because a nerve wrap was used, it is plausible that the risk of scarring would be decreased. It is possible the mechanical shear forces from the adjacent metatarsal heads on the nerve would also be decreased. Our technique does avoid direct suturing of the nerve to adjacent tissues. The likelihood of a stump neuroma is decreased. The surgical technique discussed 
in this article should be considered as a primary procedure for any patient with a common digital neuroma of the foot.

\section{References}

1. Banks AS, Vito GR, Giorgini TL (1996) Recurrent intermetatarsal neuroma: a follow-up study. J Am Podiatr Med Assoc 86(7): 299-306.

2. Barett SL, Pignetti TT (1996) Endoscopic decompression for intermetatrsal nerve entrapment. J Foot Ankle Surg 86: 299-306.

3. Cabaud HE, Rodkey WG, Nemeth TJ (1982) Progressive ultrastructural changes after peripheral nerve transection and repair. J Hand Surg $7(4): 353-365$.

4. Dellon AL (1992) Treatment of Morton's neuroma as a nerve compression. J Am Podiatr Med Assoc 82 (8): 399-402.

5. Dellon AL, Mackinnon SE (1988) Basic scientific and clinical applications of peripheral nerve regeneration. Surg Ann 20: 59-100.

6. Alexander IJ, Johnson KA, Parr JW (1987) Morton's neuroma: a review of recent concepts. Orthopedics 10(1): 103-106.

7. Betts LO (1940) Morton's metatarsalgia: neuritis of the fourth digital nerve. Med J 1L: 514-515.

8. Gauthier G (1979) Thomas Morton's disease: a nerve entrapment syndrome. A new surgical technique. Clin Orthop Relat Res 142: 90-92.

9. Redd RA, Peters VJ, Emery SF, Branch HM, Rifkin MD (1989) Morton neuroma: sonographic evaluation. Radiology 171(2): 415-417.

10. Shapiro SL (2004) Endoscopic decompression of the intermetatarsal nerve for Morton's neuroma. Foot Ankle Clin 9(2): 297-304.

11. Stamatis ED, Karabalis C (2004) Interdigital neuromas: current state of the art-surgical. Foot Ankle Clin 9(2): 287-296.

12. Williams HB (1984) The painful stump neuroma and its treatment. Clin Plast Surg 11(1): 79-83.
13. Wu KK (1996) Morton's interdigital neuroma: a clinical review of its etiology, treatment, and results. J Foot Ankle Surg 35(2): 112-119.

14. Rosson GD, Dellon AL (2005) Surgical Approach to Multiple Interdigital Nerve Compressions. J Foot Ankle Surg 44(1): 70-73.

15. Weinfeld SB, Myerson MS (1996) Interdigital neuritis: diagnosis and treatment. J Am Acad Orthop Surg 4(6): 328-335.

16. Kay D, Bennett GL (2003) Morton's neuroma. Foot Ankle Clin 8: 49-59.

17. Dellon AL (1992) Treatment of Morton's neuroma as a nerve compression. The role for neurolysis. J Am Podiatr Med Assoc 82(8): 399-402.

18. Vito GR, Talarico LM (2003) A modified technique for Morton's neuroma. Decompression with relocation. J Am Podiatr Med Assoc 93(3): 190-194.

19. Colgrove RC, Huang EY, Barth AH, Greene MA (2000) Interdigital neuroma: intermuscular neuroma transposition compared with resection. Foot Ankle Int 21(3): 206-211.

20. Wolfort Sf, Dellon Al (2001) Treatment of recurrent neuroma of the interdigital nerve by implantation of the proximal nerve into muscle in the arch of the foot. J Foot Ankle Surg 40(6): 404-410.

21. Zelent ME, Kane RM, Neese DJ, Lockner WB (2007) Minimally Invasive Morton's Neuroma Decompression. Foot Ankle Int 28(2): 263-265.

22. Villas C, Florez B, Alfonso M (2008) Neurectomy versus Neurolysis for Morton's Neuroma. Foot Ankle Int 29(6): 578-580.

23. Lee KT, Kim JB, Young KW, Park YU, Kim JS, et al. (2011) Long Term results of neurectoy in the treatment of Morton's neuroma: more than 10 years; follow-up. Foot Ankle Spec 4(6): 349-353.

24. Womach JW, Richardson DR, Murphy GA, Richardson EG, Ishikawa SN (2008) Long-term Evaluation of Interdigital Neuroma treated by Surgical Excision. Foot Ankle int 29(6): 574-577.

\section{Your next submission with Juniper Publishers will reach you the below assets}

- Quality Editorial service

- Swift Peer Review

- Reprints availability

- E-prints Service

- Manuscript Podcast for convenient understanding

- Global attainment for your research

- Manuscript accessibility in different formats

( Pdf, E-pub, Full Text, Audio)

- Unceasing customer service

Track the below URL for one-step submission https://juniperpublishers.com/online-submission.php 